R. J. Cohen and W. T. Sullivan, III, eds.

\title{
Methods and Results of Estimating Light Pollution in the Flemish Region of Belgium
}

\author{
J. Vandewalle, Dirk Knapen and Tim Polfliet
}

Bond Beter Leefmilieu Vlaanderen vzw, Federation of the Flemish environmental movement, Tweekerkenstraat 47, B 1000 Brussels, Belgium

e-mail: johan.vandewalle@bblv.be

\section{H. Dejonghe}

Vakgroep wiskundige natuurkunde en sterrenkunde, Universiteit Gent, B 9000 Gent, Belgium

e-mail: Herwig.Dejonghe@rug.ac.be

\begin{abstract}
In the Flemish region of Belgium, yearly environmental reports (MIRA) are made on the status and evolution of the environment and its policy. Since 1996 light pollution and light impediment are among the topics considered. By using indicators which can be compared in the different reports it is possible to estimate the evolution of light pollution and light impediment. Suggested changes in lighting policies could save the Flemish region as much as 18 million EURO per year.
\end{abstract}

\section{Introduction}

The first Report on the environment and nature in the Flemish region (MIRA-1) was published in summer 1994. It provided a comprehensive but above all qualitative survey of the state of the environment in the Flemish region. The second Report (MIRA-2) was published in autumn 1996. In line with the development of similar reports in other countries, the Vlaamse Milieu Maatschappij (VMM) endeavoured to survey the extent of environmental pollution in quantitative terms. The following elements were considered: (1) social and primarily economic developments which place pressure on the environment; $(2)$ the resulting impact on the quality of the environment; and (3) the effect of the quality of the environment on humans, nature and the economy. Since MIRA-2, light nuisance has been one of the topics.

MIRA-T 1998 and MIRA-T 1999 were the first thematic or T reports. These reports present a concise yet comprehensive picture of the quality of the Flemish environment in 22 chapters. Moreover, the aspiration of MIRA-2 to provide as far as possible a concise and quantitative account of the themes is further developed. To a large degree this approach has been applied to the theme of light nuisance. However, some of the key variables are as yet incomplete, because of lack of data or because they are still relatively recent and for the time being can serve only as a set of observations (Verbruggen 1998). 
This paper is mainly based on the light nuisance chapter in the aforementioned MIRA-T reports (Claeys et al. 1998; Vandewalle et al. 1999). More detailed information can be found in these reports and in the MIRA background report available from the World Wide Web (Vandewalle 1999).

\section{Definitions}

Light pollution is the increased luminosity at nighttime created by excessive use of artificial light (IDA 1997).

Light nuisance is the disruption due to artificial light experienced by humans when executing evening and night-time activities, causing either discomfort or direct blinding. Animals also suffer from light nuisance that can fragment and otherwise affect their habitats. Plants are light sensitive and therefore can change their day-night or seasonal rhythm as a result of light nuisance (IDA 1997).

The link between emissions (illumination and lighting) and immissions (pollution) is not a direct one and is influenced by the direction of the light source, the degree of cover available, reflection of the light on surfaces and the diffusion of light under certain atmospheric conditions. Since there are no exact data available on all light sources, we use extrapolation and estimations to roughly map light pollution and light nuisance in a quantitative way.

\section{Pressure: Social Developments}

A new key variable to measure the impact of social activities on light pollution and light nuisance is introduced in MIRA-T 1999. For the target group transport this variable gives the fraction of lighted road length, expressed by the formula:

$$
\frac{\sum d_{i} * r_{i}}{d_{t o t}}
$$

with $d_{i}$ the length of public roads with lighting type $i, r_{i}$ the fraction of the night that roads of lighting type $i$ are lighted and $d_{\text {tot }}$ the total public road length. The key variable varies between 0 (all roads permanently not lighted) and 1 (all roads permanently lighted). There are different types of road lighting: permanently (from sunset till dawn), evening (from sunset till $11 \mathrm{pm}$, midnight or $1 \mathrm{am}$ ), evening and morning (from sunset till $11 \mathrm{pm}$, midnight or $1 \mathrm{am}$ and from 5 , $5.30,6$ or 6.30 am till dawn). Furthermore road lighting can be uniform (e.g. one lamp every $40 \mathrm{~m}$ ), only occasional (e.g. only at crossings or dangerous curves ...), or none. The data came from a survey of local and regional authorities as well as energy-distributors.

The total road length in the Flemish region is $59,071 \mathrm{~km}$, of which $7,552 \mathrm{~km}$ is unlighted. $47,727 \mathrm{~km}$ of local and regional roads with uniform lighting are on average lighted for $94 \%$ of the night. We estimate that $2,959 \mathrm{~km}$ with occasional lighting are $10 \%$ lighted during the entire night. Some highways $(190 \mathrm{~km})$ are permanently lighted, some $(100 \mathrm{~km})$ are not lighted at all, while for the rest $(543 \mathrm{~km})$ lights go out from $0.30 \mathrm{am}$ till $5.30 \mathrm{am}$. Given these data, on average $45,666 \mathrm{~km}$ of the total $59,071 \mathrm{~km}$ was lighted in 1997 . This results in a key 
variable value for transport of 0.773 . Because of the small sample size (we received data about only $7.4 \%$ of the roads) the extrapolated data should be interpreted carefully.

For the target group agriculture we measure this key variable by taking the fraction of greenhouse surface that is lighted, corrected by the fraction of the night that the lights are on.

In the Flemish region there are 193.8 ha (4,786 acres) of greenhouses, of which 8.2 ha (202 acres) have assimilation lighting. The total number of nightly hours per annum is 4,380 , of which $1,482(33.8 \%)$ are lighted. The key variable value for agriculture is therefore 0.014 .

There is no available information about an equavalent key variable for target groups other than transport and agriculture.

Both key variables were calculated for the first time in MIRA-T 1999, based on 1997 data. By measuring the same key variables in the next MIRA reports we should be able to evaluate changes in lighting.

\section{Pressure: Use and Emissions}

For the target groups transport and agriculture we use the number of lamps and the installed power (both lamp-power and used power) as a key variable for the amount of outdoor lighting. The data on public lighting (e.g. street lighting and accent lighting of monuments) also came from the previously mentioned survey. We received data from $63 \%$ of the local communities and extrapolated these to total road length in the Flemish region. We also received complete data on regional roads which are lighted by the Flemish region. We collected data on the total number of installed lamps, the total power of these lamps ("lamp power") and the total energy-use of the installed fixtures ("net power"). For agriculture we calculated the number of lamps and power-use for assimilation lighting in greenhouses. The results are shown in Table 1.

Table 1. Number of lamps, lamp power and net power in different lamp types in public lighting and agriculture (Flemish region, 1997). Source: Bond Beter Leefmilieu 1999; Knapen 1997.

\begin{tabular}{|c|c|c|c|c|c|c|c|c|c|}
\hline & $\begin{array}{r}\text { Number } \\
\text { of } \\
\text { lamps }\end{array}$ & $\begin{array}{r}\text { Lamp- } \\
\text { power } \\
(\mathbf{k W})\end{array}$ & $\begin{array}{r}\text { Net } \\
\text { power } \\
(k W)\end{array}$ & $\begin{array}{r}\text { Number } \\
\text { of } \\
\text { Lamps }\end{array}$ & $\begin{array}{c}\text { Lamp- } \\
\text { power } \\
(k W)\end{array}$ & $\begin{array}{r}\text { Net } \\
\text { power } \\
(\mathbf{k W})\end{array}$ & $\begin{array}{r}\text { Number } \\
\text { of } \\
\text { lamps }\end{array}$ & $\begin{array}{r}\text { Lamp- } \\
\text { power } \\
(\mathrm{kW})\end{array}$ & $\begin{array}{r}\text { Net } \\
\text { power } \\
(\mathrm{kW})\end{array}$ \\
\hline $\begin{array}{r}\text { Transport } \\
\text { HgHP } \\
\text { HgLP } \\
\text { NaHP } \\
\text { NaLP } \\
\text { Other } \\
\text { Agriculture }\end{array}$ & $\begin{array}{r}1,067,190 \\
260,832 \\
194,967 \\
397,757 \\
203,370 \\
10,264\end{array}$ & $\begin{array}{r}91,685 \\
36,465 \\
3,225 \\
38,474 \\
12,526 \\
994\end{array}$ & $\begin{array}{r}120,146 \\
45,526 \\
5,030 \\
51,033 \\
17,311 \\
1,244\end{array}$ & $\begin{array}{r}198,000 \\
2,500 \\
26,000 \\
11,500 \\
158,000 \\
0\end{array}$ & $\begin{array}{r}25,413 \\
881 \\
1,170 \\
3,162 \\
20,200 \\
0\end{array}$ & $\begin{array}{r}35,035 \\
1,100 \\
1,824 \\
4,194 \\
27,916 \\
0\end{array}$ & $\begin{array}{r}1,265,190 \\
263,332 \\
220,967 \\
409,257 \\
361,370 \\
10,264 \\
68,250 \\
\end{array}$ & $\begin{array}{r}117,098 \\
37,346 \\
4,395 \\
41,636 \\
32,726 \\
994 \\
27,300 \\
\end{array}$ & $\begin{array}{r}155,181 \\
46,626 \\
6,854 \\
55,228 \\
45,227 \\
1,245 \\
36,210 \\
\end{array}$ \\
\hline
\end{tabular}

Not all installed lamps are switched on during the entire night. In Figure 1 we show how the total installed lamp power is used during the night. $11.7 \%$ of the public lighting is turned off at night (14.4\% of the installed power), and $7.7 \%$ of the lamps (9.9\% of the installed power) are switched on again during the morning. The average number of lighting hours was 4,112 in 1997, from a total of 4,380 nightly hours. This is an increase of $3.8 \%$ compared to 1996 . 


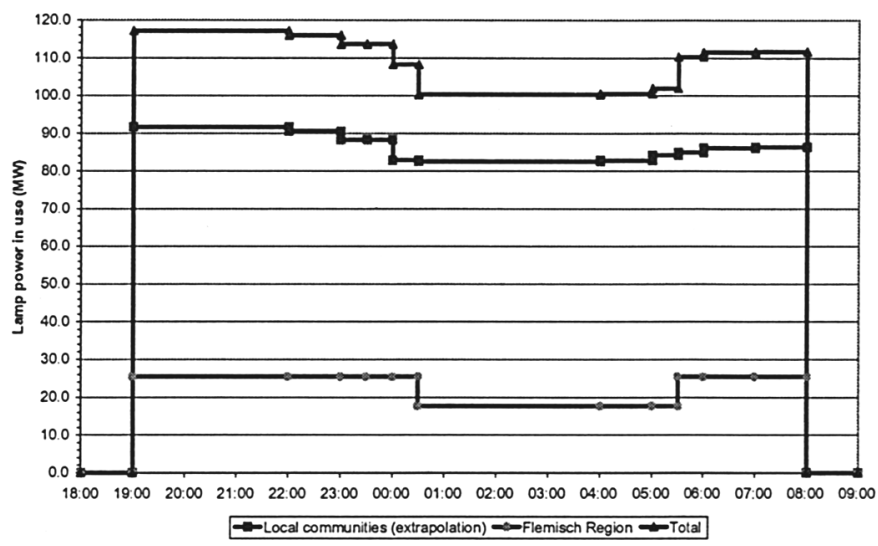

Figure 1. Use of public lighting during night. Lamp power (MW) switched on in the Flemish region in 1997. Source: Bond Beter Leefmilieu 1999.

Table 2. Number of lamps and power in different applications in 1997. Source: Bond Beter Leefmilieu 1999.

\begin{tabular}{lccc}
\hline & \multicolumn{3}{c}{ Flemish region } \\
& lamps (n) & Lamp power (MW) & Net power (MW) \\
\hline Transport & & & \\
street lighting & $1,208,581$ & 115.5 & 152.4 \\
accent lighting & 56,609 & 1.6 & 2.7 \\
total & $1,265,190$ & 117.1 & 155.1 \\
Agriculture & & & \\
assimilation lighting & 68,250 & 27.3 & 36.2 \\
\hline
\end{tabular}

In $1997,4.5 \%$ of the lamps (1.4\% of the lamp power and $1.7 \%$ of net power) in public lighting were used for accent lighting. In agriculture, $27.3 \mathrm{MW}$ of lamp power (36.2 MW net power) is installed for assimilation lighting in greenhouses. Data about photoperiodic lighting are not available.

The amount of upward light flux is proportional to the power of the upward lighting at a certain moment and also depends on other factors such as weather and air pollution. We define a key variable $U L F$ for the amount of upward lighting flux with the formula:

$$
U L F=0.58 K V+0.224 S V+0.09 A V+0.30 R V(\text { inM } W) .
$$

with $K V=$ net power of installed Accent Lighting,

$S V=$ net power of installed Street Lighting,

$A V=$ net power of installed Assimilation Lighting,

$R V=$ net power of installed Rest Lighting (all other outdoor lighting).

The upward light power of Accent Lighting is estimated as $40 \%$ of the installed power directly and $30 \%$ of the rest after reflection, giving $58 \%$ of the 
installed power. The same applies for Street Lighting with $3 \%$ of the installed power directly and $20 \%$ of the rest after reflection, giving $22.4 \%$ of the installed power. For Assimilation Lighting in greenhouses we estimate that $5 \%$ of the installed power is lost through the greenhouse roof ( $25 \%$ has no roof cover, roofs form $84 \%$ of the greenhouse surface and the reflection is about $25 \%$ ) and $4 \%$ is lost through the greenhouse sides $(95 \%$ has no side cover, sides form $16 \%$ of the greenhouse surface and the reflection is about 25\%). For the Rest Lighting we estimate that $30 \%$ of the installed power is spilt towards the sky (both directly and after reflection). The key variable is shown in Table 3.

Table 3. Upward light flux from the Flemish region 1996 - 1997. Source: Bond Beter Leefmilieu 1999.

\begin{tabular}{lcc}
\hline Target group & \multicolumn{2}{c}{ Upward Light Flux } \\
& 1996(MW) & 1997 (MW) \\
\hline Transport & & \\
street lighting & 33.8 & $32.1-34.1^{a}$ \\
accent lighting & 0.8 & $1.5-1.6^{a}$ \\
Agriculture & & \\
assimilation lighting & & $3.1-3.4^{b}$ \\
Rest & $18.9-61.5^{c}$ & $19.2-60.6^{c}$ \\
Total & $53.5-96.1$ & $55.9-99.7$ \\
\hline
\end{tabular}

${ }^{a}$ dispersion due to different data sets (lowest $=$ identical to 1996, highest data from inquiry)

${ }^{b}$ dispersion due to uncertainty about greenhouse area

${ }^{c}$ dispersion due to wide margins in estimation of proportion of outdoor lighting in total energy use for the different target groups.
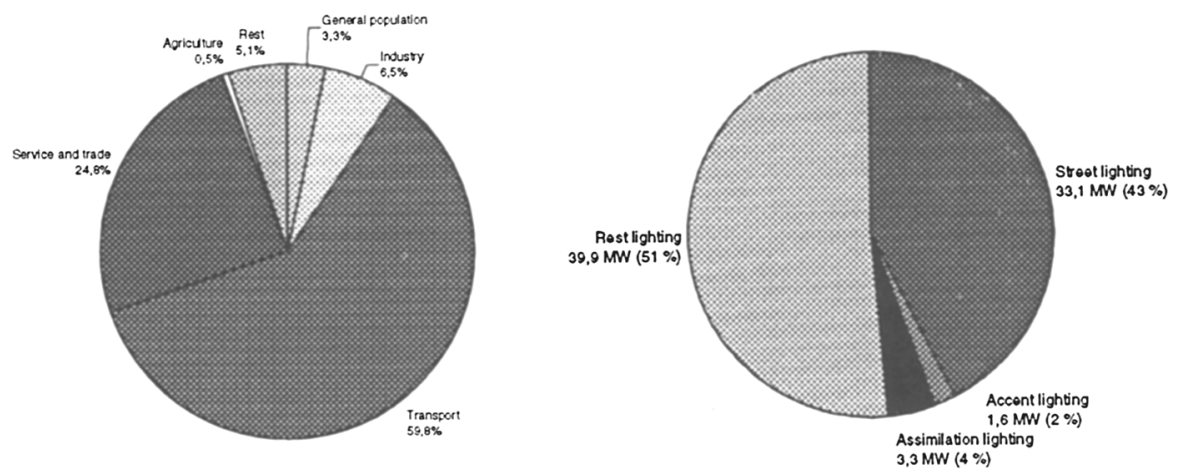

Figure 2. Contribution of target groups to Left: the amount of outdoor lighting and Right: the upward lighting, for the Flemish region, 1997. Source: Bond Beter Leefmilieu 1999. 
The contribution of the different target groups in the amount of outdoor lighting is estimated by their energy use. Furthermore, we calculated the contribution of the target groups to the upward lighting flux. Results are shown in Figure 2.

We conclude that target groups (summed in the rest term) other than street lighting form an important contribution to the total upward lighting flux. More detailed information is needed to improve our rough estimates and to determine the amount of the different target groups.

Assimilation Lighting is responsible for twice as much upward lighting flux compared with Accent Lighting. Despite the greater fractional loss of light in Accent Lighting (2.5 times that lost in Street Lighting with the same power use) it accounts overall only a few percent of the upward lighting flux compared to Street Lighting.

\section{State: Immissions}

Satellites of the Defense Meteorological Satellite Program (DMSP) of the US Air Force circle round the Earth at about $830 \mathrm{~km}$ height. They have several instruments on board such as the Operational Linescan System (OLS) The DMSP-OSL system is sensitive enough to detect light souices of urban, industrial and other anthropogenic origin, even at full moon.

We used the technique developed by Imhoff et al. (1997) to make a light pollution map of the Flemish region. Figure 3 was created out of 231 images from October 1994 till March 1995 from the F-10 and F-12 satellites taken at $9.30 \mathrm{pm}$ local time. We calculated the proportion of times a pixel is recognised as a light-emitting source out of the cloud free images. By doing this we only observe stable light sources and not temporary sources such as fires or lightning. Because each pixel shows an area of $2.7 \mathrm{~km} \times 2.7 \mathrm{~km}$, sources such as roads aren't visible. Urban agglomerations on the other hand are clearly visible, as are the industrial complexes near the major waterways and the main greenhouse area. Information from these images is relevant for astronomers who search for suitable locations to observe the skies.

\section{Proposed Measures}

We calculated the impact and costs of three measures to restrict light pollution. The first one is replacing all mercury vapour lamps in public lighting with highpressure sodium vapour lamps. The second one is to change both the lamps and the fixtures and the third is to put all public lighting out between midnight and $6 \mathrm{am}$.

Changing all mercury vapour lamps would save an energy use of about $103 \mathrm{GWh}$ a year or $17 \%$ of the yearly energy use for public lighting. This measure does save a lot of energy, but does not reduce light pollution.

If, on the other hand, one changed not only the lamps but also the old (and bad) fixtures of these same lamps, one would save another $23 \mathrm{GWh}$ a year or $3.9 \%$ of the yearly energy use in public lighting and one would significantly reduce light pollution (no exact figure could be calculated). The changing of 


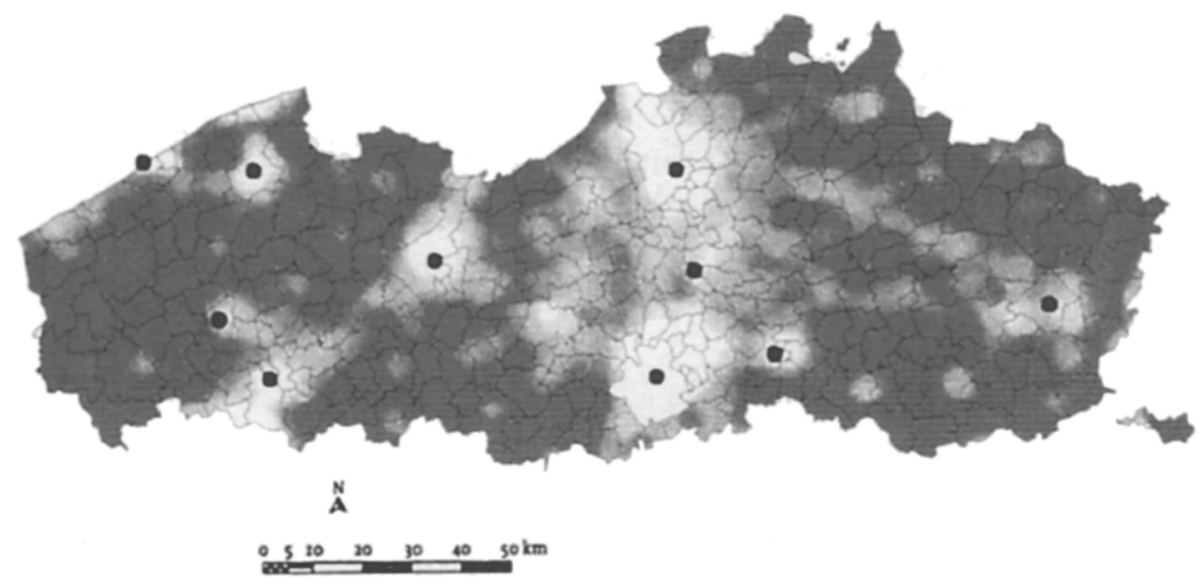

Figure 3. Light pollution in the Flemish region as seen from the sky (October 1994 till March 1995). Source: VITO 1998, NOAA/NGDC 1994-1995.

fixtures could also be extended to current old (or bad) fixtures that already use sodium vapour lamps. We cannot calculate the possible savings of this extended measure because we don't know how many of the current fixtures with sodium vapour lamps are bad.

Extinguishing all public lighting between midnight and 6 am gives a saving potential of $296 \mathrm{GWh}$ a year or $49 \%$ of the yearly energy use for public lighting. If authorities wish to consider extinguishing all lights they should take into account the positive social effects of continuous public lighting such as ensuring (traffic) safety. It could be preferable to decrease the public lighting selectively (e.g. $50 \%$ ), so that crossings with high nightly traffic density, dangerous curves, etc. would remain lit. This option implies extra costs such as in different scheduling, distance control, etc. One should balance the pros and cons against each other.

Taking the three measures together gives a potential saving of $362 \mathrm{GWh}$ per year, or $60 \%$ of the present yearly energy use in public lighting.

Despite the low energy price local authorities pay (0.034 EURO per $\mathrm{kWh}$ between $10 \mathrm{pm}$ and $6 \mathrm{~mm}$ and $0.096 \mathrm{EURO}$ per $\mathrm{kWh}$ between $6 \mathrm{am}$ and $10 \mathrm{pm}$ ) the yearly financial saving for all authorities (local and Flemish) is $18 \times 10^{6}$ EURO. To achieve this saving, 484,299 fixtures with mercury vapour lamps would need to be changed. The installation of a new (efficient) fixture with sodium vapour lamps costs 211 EURO. The total cost is therefore $102 \times 10^{9}$ EURO, and in less than 6 years the costs for this investment would be recovered. 


\section{References}

Claeys, S., Vandewalle, J. \& Dejonghe, H. 1998, Lichthinder. In: Verbruggen, A. (ed.) (1998) Milieu- en natuurrapport Vlaanderen: thema's MIRA-T 1998. Eerste druk, D/1998/5779/32, SIBN 90-5350-726-4, NUGI 825/693, Vlaamse Milieumaatschappij en Garant Uitgevers nv.

International Dark-Sky Association 1997, Glossary of Basic Terms and Definitions. Information Sheet 9, April 1997.

Imhoff, M.L. et al. 1997, A Technique for Using Composite DMSP/OLS "City Lights" Satellite Data to Map Urban Area. Remote Sens. Environ. 61:361-370.

Knapen, J. 1997, Written announcement. BVV (Belgische Vereniging voor Verlichtingskunde), 22/12/1997.

Vandewalle, J. 1999, Lichthinder. In: Vandeweerd, V. (ed.) (1999) Milieu- en natuurrapport: Achtergronddocument. http://www.vmm.be/milieu/mil_mira_ag.html

Vandewalle, J., Knapen, D., Polfliet, T. \& Dejonghe, H 1999. Lichthinder. In: Vandeweerd, V. (ed.) (1999) Milieu- en natuurrapport Vlaanderen: thema's MIRA-T 1999. Eerste druk, D/1999/5779/40, ISBN 90-5350870-8, NUGI 825/693, Vlaamse Milieumaatschappij en Garant Uitgevers nv.

Vandeweerd, V. (ed.) 1999, Report on the environment and nature in Flanders: themes MIRA-T 1999. First Edition, D/1999/5779/40, ISBN 90-5350870-8, NUGI 825/693, Vlaamse Milieumaatschappij and Garant Uitgevers nv.

Verbruggen, A. (ed.) 1998, Report on the environment and nature in Flanders: themes MIRA-T 1998 summary. First Edition, D/1998/5779/32, SIBN 90-5350-726-4 NUGI 825/693, Vlaamse Milieumaatschappij and Garant Uitgevers nv. 